УДК 130.2

DOI 10.18413/2712-746X-2020-45-1-183-188

\title{
«ИДЕАЛЬНАЯ» БИБЛИОТЕКА. О СОХРАНЕНИИ ЗНАНИЯ СЕГОДНЯ
}

\section{"PERFECT" LIBRARY. ABOUT KEEPING KNOWLEDGE TODAY}

\author{
К.И. Черкесова, С.М. Шарабарин \\ K.I. Cherkesova, S.M. Sharabarin \\ Белгородский государственный институт искусств и культуры, \\ Россия, Белгород, 308033, Королёва ул. 7 \\ Belgorod State Institute of Arts and Culture, \\ 7 Koroleva St, Belgorod, 308033, Russia, \\ E-mail: fin@bgiik.ru
}

\begin{abstract}
Аннотация
Развитие технологий сохранения информации в настоящий момент связано со сложными процессами унификации и специализации знания. Такая ситуация определяется использованием программного кода. Одной из главных причин кризиса современных механизмов сохранения знания является неограниченность объема информации, хранимой на цифровом носителе. Другой не менее важной причиной является все больший вывод информации из памяти человека в машинную память, что также дает возможность человеку создать собственный, гибридный механизм сохранения знания. Обратная сторона данного процесса заключена в динамичном развитии механизмов беспамятства.

Abstract

The development of information storage technologies, at most, is currently associated with complex processes of unification and specialization of knowledge. This situation is determined by the use of program code. One of the main causes of the crisis of modern mechanisms for maintaining knowledge is the unlimited amount of information stored on a digital medium. Another equally important reason is the increasing output of information from a person's memory to machine memory, which also enables a person to create his own mechanism for preserving knowledge. The reverse side of this process lies in the dynamic development of mechanisms of unconsciousness.
\end{abstract}

Ключевые слова: культура, знание, информация, современность, память, техника. Key words: culture, knowledge, information, modernity, memory, technology.

\section{Введение: философия и кибернетика}

В 1966 году журнал Шпигель опубликовал интервью с Мартином Хайдеггером, в котором на вопрос, что сегодня приходит на смену философии, он дает достаточно интересный ответ - кибернетика. Вместо ожидаемых наук, возможно, менее ожидаемой литературы, мы сталкиваемся с наукой, изучающей информацию, её возникновение, сохранение и передачу. Причем неожиданно не кибернетика сама по себе, а то, что именно она сменяет (или меняет?) философию.

Для самого М. Хайдеггера такой ответ обоснован связью кибернетики и техники. Последняя необходима для удовлетворения потребностей человека, представляя из себя (здесь можно понимать эту фразу практически буквально), являя собой инструментальность. Инструментальность, в свою очередь, отсылает к причине и её пониманию Аристо- 
телем и далее - к фундаментальной проблеме возникновения. М. Хайдеггер проблему про-изведения или по-явления, явленности чего-либо как результата соединения причин, основывает «на раскрытии потаенности», на которой и «стоит всякое про-из-ведение. Последнее, со своей стороны, собирает в себе четыре вида повода - всю причинность - и правит ими. К сфере причинности относятся цель и средства, относится инструментальное. Инструментальность считается основной чертой техники. Шаг за шагом спрашивая, что такое собственно техника как средство, мы придем к раскрытию потаенного... Итак, техника не простое средство. Техника - вид раскрытия потаенности. Если мы будем иметь это в виду, то в существе техники нам откроется совсем другая область. Это - область выведения из потаенности, осуществления истины» [Хайдеггер, 2007, с. 311]. Здесь становится ясна позиция М. Хайдеггера, который говорит о смене философии, имеющей дело с истиной, кибернетикой, имеющей дело с техникой, которая сегодня раскрывает истину.

Можно сказать, что философия, являясь сугубо человеческим делом на протяжении всей своей истории, впервые сталкивается с нечеловеческим в лице техники, и это, на наш взгляд, составляет основной предмет удивления в ответе М. Хайдеггера. При этом вопрос о человеке и технике можно отсчитывать от античного мифа о Прометее и Эпиметее, когда в западной традиции мысли, философской в последующем, оформляется связка, в которой присутствуют человек, знание, техника и память. Сегодня, беря во внимание ответ М. Хайдеггера, мы можем поставить несколько иной вопрос: действительно ли техника сохраняет знание? Он несколько отличается от вопроса о раскрытии истины, поскольку открытие и сохранение - не одно и то же, равно как не равнозначны истина и знание.

Однако эти вопросы связаны проблемой памяти. Открыть или раскрыть - еще не значит сохранить, но традиционно ценность имеет именно сохраненное знание, которое если и не является истинным, то стремится таковым быть. Сама философия как практика мысли, школа мысли и традиция более связана с сохранением, а не одномоментным раскрытием истины. Наконец, мы можем сформулировать наш вопрос о сохранении знания как вопрос о библиотеке, том месте, в котором знание хранится. Сегодня это вопрос о технике также, или даже преимущественно, о технике. Образно говоря, человек, знание, техника и память «встречаются» или должны встретиться в «идеальной» библиотеке.

\section{Контексты}

Отметим, что контекст обозначенной нами проблемы достаточно обширен. Проблема знания восходит к трудам софистов и Сократа, Демокрита, Платона и Аристотеля, а как более частная проблема культуры и знания, письменности и знания находит отражение в работах С.С. Аверинцева, И.Р. Блохина, Т.В. Васильева, Ю.С. Довженко, А.Б. Егорова, Ф.Х. Кессиди, М.А. Коростовцева, А.Ф. Лосева, А.С. Мельникова, А.В. Петрова. Исторический аспект сохранения знания можно найти в работах Х. Арендт, Р. Барта, П. Бурдьё, Ф. Гваттари, А. Грамши, Ж. Ле Гоффа, Ж. Делёза, И. Иллича, А. Де Либера, Б. Кларка, Б. Латура, Дж. Нидама, М. Полани, Д. Прайса, М. Сюриа, М. Фуко, У. Эко.

Дж. Агамбен, Ж. Бодрийяр, Ги Дебор, Г. Стэндинг, С. Жижек составляют необходимый (но, далеко не полный) перечень авторов для осмысления проблемы сегодня. Как и работы, посвященные проблеме языка и коммуникации, символа и знака, представленные трудами М. Бахтина, В. Беньямина, П. Верильо, В. Гриценко, Р. Дебрэ, Ю. Лотмана, В. Савчука, Ф. Киттлера, М. Куртова, Л. Мамфорда, Й. Хейзинги, Д. Хезмондалша, Р. Кайуа. Особо отметим исследования М.К. Петрова, который был первым из отечественных авторов, специально занимавшихся проблемой сохранения и передачи знания.

\section{От «галактики Гутенберга» к галактике медиа}

По меркам истории совсем недавно Маршал Мак-Люэн писал о закате «галактики Гутенберга», характеризуя современность через активное развитие медиа. Именно медиа 
преодолевают границы человекоразмерности (понятие М.К. Петрова), связанные с книгой. При этом мы говорим о наиболее устойчивой из «машин» или сборок, позволяющих сохранять знание, которая успешно функционировала, начиная с античности, и в полной мере раскрылась в средневековье, представляя собой «мега-машину», объединяющую в себе человека - книгу - библиотеку и монастырь [Борисов, Черкесова]. Начиная с эпохи Нового времени, эта «сборка» или сеть (здесь мы достаточно близки к пониманию Ж. Делеза) [Борисов, Игнатов, Римский, 2017] сохранения знания трансформируется под влиянием целого комплекса факторов. Для нас важно то, что монастырские библиотеки заменяются национальным государством и публичной библиотекой. Возникшая «мега-машина» включает человека - книгу - библиотеку - государство. История трансформации «машин» сохранения знания показывает, что по мере их развития техника занимает в них все большее место. Печатная книга увеличивает эту долю по сравнению с рукописной книгой, и тем более техническое тотально присутствует в сохранении знания сегодня. Возможно, замечание М. Хайдеггера о том, что техника связана со знанием практически на генетическом уровне, греческие слова «технэ» и «эпистеме» оба означали знание и вели к раскрытию истины, сегодня верно как никогда.

С чем связана произошедшая «революция медиа»? Прежде всего с тем, что машина сохранения знания снова изменяется, библиотека все более трансформируется из государственной в частную (заявления о непопулярности чтения связаны именно с этим, с упадком библиотеки как значимого института, места локализации знания), перемещаясь в электронное устройство, виртуальное хранилище конкретного человека. Р. Дебрэ предлагает достаточно адекватное понятие «медиасфера», определяющим для которой будет смысл охвата, когда человек выстраивает собственные конфигурации информации и её источников, которые эту сферу формируют и наполняют [Дебрэ, 2010]. При этом стоит также уточнить, что человек становится как производителем информации (творцом библиотеки в непосредственном смысле), так и собирателем (коллекционером уже не книг, а информации), подчас достаточно активным центром, который «стягивает» информацию к себе или вокруг себя, образуя действительно сферу. И эта сфера объединяет уже не только человека и информацию (знание, контент), но и технику (этот последний пункт часто упускают из виду). Отчасти это ситуация демиурга, в которую поставлен современный человек, вынужденный творить собственный мир или даже миры (виртуальные реальности сетевого мира).

М.А. Игнатов пишет об ответственности человека в такой ситуации: «... в мире, основанном на нестабильности и созидательности, человечество опять оказывается в самом центре законов мироздания, а Вселенная представляет собой когерентное образование, где все события взаимосвязаны. Это значит, что первостепенной важности задачей для наших современников становится забота о глобальном, целостном взгляде на мир, открывая новые горизонты выхода человека за пределы современной сетевой цивилизации. Тем самым с необходимостью раскрывая перед человечеством возможность выбора, означающую предельную этическую ответственность» [Игнатов, 2018, с.132]. Здесь мы остановимся в развитии этической темы, указав на демиургичность человека сетевой культуры и его свободу.

\section{Экран: показать скрывая}

Виртуальные миры подобны полкам идеальной библиотеки, вход в которую осуществляется через достаточно интересное в философском плане устройство, представляющую собой поверхность (кстати, достаточно популярный концепт современной философии). На это указывает само слово, которым обозначается поверхность, отображающая то, что мы вводим в электронное устройство (компьютер, телефон) и то, что выводится экран. Дж. Агамбен указывает на то, что этимологически слово «поверхность» восходит к древненемецкому skirmjan, имеющему значение «защищать, прикрывать, оборонять», и далее задает вопрос: «Как могло случиться, что слово, означающее «препятствие, прикры- 
тие», приобрело смысл «поверхности, на которой появляются образы»?» [Агамбен, 2015, c. 128]. Агамбен находит ответ в том, что текст отрывается от страницы, своего материального носителя, и воспринимается как нечто самостоятельное. Экран скрывает не что иное, как свою собственную материальность, равно как и материальность машины: «Цифровое устройство не является нематериальным, но оно основано на стирании собственной материальности: экран «служит завесой» от самого себя, прячет страницу-носитель - материю - в странице-письменности, действительно ставшей нематериальной или, скорее, призрачной, если призрак является чем-то утратившим свое тело, но каким-то образом сохранившим свою форму» [Агамбен, 2015, с. 129]. Сокрытие материальности можно также рассматривать как одну из сторон работы машины сохранения знания в её модальности машины забывания, в данном случае - о себе самой как материальной.

Иными словами, то, что экран скрывает не только свою материальность, материальность машины, но само сокрытие в противоположность идее М. Хайдеггера о раскрытии машиной истины, играет здесь главную роль. Другой вопрос: что скрывает машина, помимо своей материальности? Если обратить внимание на проблему памяти и времени, можно отметить высказывание В.П. Римского о том, что «главным временем индустриализма... становится рабочее время, время труда» [Мельник, Римский, 2014, с. 143], и предположить, что время постмодерна становится временем вне труда или временем убегания от труда и тем самым временем забвения, а машины сохранения знания -машинами его забывания.

Многие ученые в своих исследованиях так или иначе затрагивали вопросы о времени игры и праздника. Характерную для игрового времени сиюминутность и повторяемость в своих трудах отражал и Й. Хейзинг. Особенность игры заключается в том, что она может быть сыграна непременно либо в любой другой момент времени, а также повторена сколько угодно раз. Следует уточнить, что в этот момент происходит прерывание текущего времени, а также возникает разрыв в его размеренном течении. Такая же ситуация наблюдается и с самим пространством игры, которое представляет собой некое специфическое образование среди привычных пространств: «Подобно тому как формально отсутствует какое бы то ни было различие между игрой и священнодействием, то есть сакральное действие протекает в тех же формах, что и игра, так и освященное место формально неотличимо от игрового пространства. Арена, игральный стол, магический круг, храм, сцена, киноэкран, судебное присутствие - все они по форме и функции суть игровые пространства, то есть отчужденная земля, обособленные, выгороженные, освященные территории, где имеют силу свои особые правила. Это временные миры внутри мира обычного, предназначенные для выполнения некоего замкнутого в себе действия» [Хейзинга, 2011, c. 34-35]. «Для человека, убежденного в культурной продуктивности игр и даже видящего в них один из главных факторов цивилизации, существование и популярность игровых автоматов неизбежно указывают на пробел в его системе. Отныне ему придется принимать их в расчет. Он уже определил, что игры не в равной мере плодотворны, что одни из них больше других способствуют счастливому развитию искусств, науки и морали, поскольку в большей степени обязывают к соблюдению правил, к добросовестности, самообладанию, бескорыстию или же требуют больше расчетливости, воображения, терпения, ловкости или силы. Но вот теперь перед ним какие-то пустые, ничтожные игры, не требующие от игрока ничего и представляющие собой просто бесплодное проведение досуга.

Такие игры буквально убивают время, не делая его плодотворным, тогда как настоящие игры подобны посеву, который принесет урожай еще нескоро, почти случайно, во всяком случае без заранее установленной цели и как бы прилагаясь к удовольствию» [Кайуа, 2007, с. 194].

Ги Дебор по существу этой связи критически пишет: «Вся жизнь обществ, в которых господствуют современные условия производства, выступает как огромное скопление спектаклей. Все, что раньше составляло прямой жизненный опыт, теперь отдалилось в 
представление... Спектакль при его рассмотрении во всей полноте является одновременно итогом и проектом существующего способа производства. Он служит дополнением к реальному миру, добавленной к нему декорацией» [Ги Дебор, 2015, с. 98].

Время также рассматривается Ги Дебором как время-производство и время-товар. «Псевдоциклическое время - это время потребления современного экономического выживания, возросшего выживания, где в повседневной жизни по-прежнему отсутствует выбор, и оно подчинено уже не природному порядку, а псевдоприроде, сформировавшейся в ходе становления отчужденного труда. Такое время естественным путем восстанавливает старинный циклический ритм, который управлял выживанием доиндустриальных сообществ» [Ги Дебор, 2015, с. 126].

В. Мазин находит в этой схеме «человек - техника» также неожиданное место для языка. Он пишет: «Протезы деконструируют оппозицию искусственное / естественное, техне / фюсис. Природа человека вне природы. Технология как бы отчуждает человека от самого себя, от собственного смысла бытия, но именно она и придает ему этот смысл. Человек - между так называемым природным и так называемым техническим в себе. Он - в восполнительности; его живое присутствие всегда уже конструировано фантазматическим, протезирующим отсутствием. Зазор возникает в связи с работой дискурсивной машины письма» [Мазин, 2010, с. 232].

\section{Заключение. «Идеальный» читатель}

Возвращаясь к началу, высказыванию М. Хайдеггера о замене философии кибернетикой, можно согласиться с тем, что традиция (философская также), как память, заменена техникой отчасти уже сегодня, но «работает» техника и обратным образом, не только сохраняя, но и способствуя, стимулируя беспамятство. «Машин памяти» не существует без «машин беспамятства». Идеальная библиотека, которую мы попытались себе представить, дополняет столь же идеальный читатель, приходящий в нее каждый раз как в первый. И более того, перефразируя М. Хайдеггера, можно сделать предположение, что философия всегда и была кибернетикой, по крайней мере в том смысле, что указывала на пределы противостояния человека и техники, культуры и техники, природы и культуры, а также машин памяти и машин беспамятства. Через раскрытие мнимости этих оппозиций, откроется новая перспектива для развития человека. Она связана со свободой хранения знания в своей голове без внешних технических «протезов», в том числе и облачных, частных или коллективных.

\section{Список литературы}

1. Агамбен Дж. 2015. Костер и рассказ. М., Грюндриссе, 192 с.

2. Бахтин М.М. 1990. Творчество Франсуа Рабле и народная культура средневековья и Ренессанса. М., Худож. лит., 563 с.

3. Борисов С.Н., Игнатов М.А., Римский В.П. 2017. Сетевая парадигма в номадологии Ж. Делёз. В кн.: Культурная жизнь Юга России. № 3 (66): 13-16.

4. Борисов С.Н., Черкесова К.И. 2018. Социокоды и технологии хранения информации в первобытной культуре. Научные ведомости Белгородского государственного университета. Серия: Философия. Социология. Право. Т. 43. № 3: 443-448.

5. Ги Дебор. 2015. За и против кинематографа. М., Гилея, 340 с.

6. Дебрэ Р. 2010. Введение в медиологию. М., Праксис, 368 с.

7. Игнатов М.А. 2018. Сетевая парадигма в культуре и науке. Белгород, НИУ «БелГУ», 158 с.

8. Кайуа Р. 2007. Игры и люди: Статьи и эссе по социологии культуры. М., ОГИ, 304 с.

9. Мазин В. 2010. Субъект Фрейда и Деррида. СПб., Алетейя, 256 с.

10. Мельник Ю.М., Римский В.П. 2014. Время жить и время созерцать... Экзистенциальные смыслы и философское понимание времени в классической европейской культуре. СПб., Алетейя, 184 с.

11. Хайдеггер М. 2007. Время и бытие. Статьи и выступления. СПб., Наука, 621 с.

12. Хейзинга Й. 2011. Нomo ludens. Человек играющий. СПб., Изд-во Ивана Лимбаха, 416 c. 


\section{References}

1. Agamben Dzh. 2015. Koster i rasskaz. [Bonfire and story]. M., Gryundrisse, 192 p.

2. Bahtin M.M. 1990. Tvorchestvo Fransua Rable i narodnaya kul'tura srednevekov'ya i Renessansa. [Creativity of Francois Rabelais and folk culture of the middle ages and Renaissance]. M., Hudozh. lit., 563 p.

3. Borisov S.N., Ignatov M.A., Rimskij V.P. 2017. Setevaya paradigma v nomadologii ZH. Delyoz. [Network paradigm in nomadology by J. Deleuze]. Kul'turnaya zhizn' YUga Rossii. In the book.: [Cultural life in the South of Russia]. № 3 (66): 13-16.

4. Borisov S.N., CHerkesova K.I. 2018. Sociokody i tekhnologii hraneniya informacii v pervobytnoj kul'ture [Sociology and technology information storage in a primitive culture]. Nauchnye vedomosti Belgorodskogo gosudarstvennogo universiteta. Seriya: Filosofiya. Sociologiya. Pravo. Vol. 43. № 3: 443-448. (in Russian)

5. Gi Debor. 2015. Za i protiv kinematografa. [For and against cinema]. M., Gileya, 340 p.

6. Debre R. 2010. Vvedenie v mediologiyu. [Introduction to mediology]. M., Praksis, 368 p.

7. Ignatov M.A. 2018. Setevaya paradigma v kul'ture i nauke. [Network paradigm in culture and science]. Belgorod, NIU «BelGU», 158 p.

8. Kajua R. 2007. Igry i lyudi; Stat'i i esse po sociologii kul'tury. [Games and people: Articles and essays on the sociology of culture]. M., OGI, $304 \mathrm{p}$.

9. Mazin V. 2010. Sub"ekt Frejda i Derrida. [Subject of Freud and Derrida]. SPb., Aletejya, 256 p.

10. Mel'nik YU.M., Rimskij V.P. 2014. Vremya zhit' i vremya sozercat'... Ekzistencial'nye smysly i filosofskoe ponimanie vremeni v klassicheskoj evropejskoj kul'ture. [Time to live and time to contemplate ... Existential meanings and philosophical understanding of time in classical European culture]. SPb., Aletejya, $184 \mathrm{p}$.

11. Hajdegger M. 2007. Vremya i bytie. Stat'i i vystupleniya. [Time and being. Articles and speeches]. SPb., Nauka, 621 p.

12. Hejzinga J. 2011. Homo ludens. CHelovek igrayushchij. [Homo ludens. A man playing]. $\mathrm{SPb}$., Izd-vo Ivana Limbaha, 416 p.

\section{Ссылка для цитирования статьи For citation}

Черкесова К.И., Шарабарин С.М. 2020. «Идеальная» библиотека. О сохранении знания сегодня. NOMOTHETIKA: Философия. Социология. Право. 45 (1): 183-188.

DOI 10.18413/2712-746X-2020-45-1-183-188

Cherkesova K.I., Sharabarin S.M. 2020. "Perfect" library. About keeping knowledge today. NOMOTHETIKA: Philosophy. Sociology. Law series. 45 (1): 183-188. (in Russian).

DOI 10.18413/2712-746X-2020-45-1-183-188 